\title{
Informal Fallacies as Cognitive Heuristics in Public Health Reasoning
}

\author{
LOUISE CUMmings
}

School of Arts and Humanities

Nottingham Trent University

Clifton Campus, Clifton Lane

Nottingham, NG11 8NS

England, UK

louise.cummings@ntu.ac.uk

\begin{abstract}
The public must make assessments of a range of healthrelated issues. However, these assessments require scientific knowledge which is often lacking or ineffectively utilized by the public. Lay people must use whatever cognitive resources are at their disposal to come to judgement on these issues. It will be contended that a group of arguments - so-called informal fallacies - are a valuable cognitive resource in this regard. These arguments serve as cognitive heuristics which facilitate reasoning when knowledge is limited or beyond the grasp of reasoners. The results of an investigation into the use of these arguments by the public are reported.
\end{abstract}

Résumé: Le public doit faire des évaluations d'un éventail de questions liées à la santé. Cependant, ces évaluations nécessitent des connaissances scientifiques que souvent le public n'a pas ou utilise mal. Les profanes doivent utiliser toutes les ressources cognitives qui sont à leur disposition pour aboutir à un jugement sur ces questions. Il sera soutenu qu'un groupe d'arguments - soidisant sophismes non formels - sont une ressource cognitive précieuse à cet égard. Ces arguments servent d'heuristiques cognitives qui facilitent le raisonnement lorsque la connaissance est limitée ou au-delà de la compréhension des raisonneurs. On signale les résultats d'une enquête sur l'utilisation de ces arguments par le public.

Keywords: argument from authority, argument from ignorance, cognitive heuristic, informal fallacies, public health, reasoning

\section{Introduction}

There are few scientific disciplines that demand the engagement of the public quite like public health science. None of us are beyond the expansive reach of this important health-based science. Whether we are making decisions about the safety of the swine flu immunization for our children, considering whether to discontinue the use of the oral contraceptive pill following concerns about thrombosis or opting to remove beef from our diet 
due to fears about bovine spongiform encephalopathy (BSE), public health issues are never far from the daily deliberations of the public. To the extent that the public must engage with public health problems, it is at least relevant to ask if it is adequately equipped to do so. Studies of scientific literacy would tend to suggest not. Findings indicate a lack of knowledge of scientific facts and method ${ }^{1}$ with little evidence of improvement over time and some concern that scientific literacy amongst the public may actually be decreasing. ${ }^{2}$ Commentators have described how an 'attentive' segment of the population-less than 20\%-has sufficient knowledge of and interest in science to assess issues that are characterized by complexity and expert uncertainty. ${ }^{3}$ At the same time as the public's knowledge of scientific issues appears to be compromised, there is a growing demand for the public to engage with increasingly complex scientific problems. Many of these problems are so complex that they are beyond the current knowledge levels of scientists themselves (e.g., climate change). Even when scientists do have a good understanding of the processes involved in a scientific or public health phenomenon, these processes may be so complex as to be beyond the cognitive grasp of the lay person. It emerges that the public is confronted

${ }^{1}$ In the Science and Engineering Indicators 2010 (National Science Board, 2010: 7-19), for example, it was reported that in 2008 only 47 per cent of US males questioned and 60 per cent of US females correctly identified that the statement Antibiotics kill viruses as well as bacteria is false. Even less were subjects able to answer a question that was designed to test their understanding of the scientific method. In 2008, a mere 37 per cent of males and 39 per cent of females understood that the effectiveness of a drug for blood pressure could only be tested if a control group, that did not receive the drug, was also included in the experimental design.

${ }^{2}$ In a Technical Report prepared by the American Public Health Association (APHA) in 1990, APHA remarked: 'It is apparent that the escalation of scientific knowledge has not been paralleled by enhanced public understanding of science in the US, at least as measured by testing in schools, or in the United Kingdom. Indeed, among US junior and senior high school students, comprehension of and achievement in science are below that of two decades ago. Most adults in the US, whether they bear responsibility for decisions at the governmental, public, or personal level, are inadequately versed in science and its methods' (APHA, 1990: 748). Between 1992 and 2008, the number of correct answers to scientific literacy questions posed to US adults varied little, with the mean number of correct responses to nine questions exceeding five but never attaining six (National Science Board, 2010: 7-18).

${ }^{3}$ Doble (1995: 95) attributes this claim to Jon Miller of Northern Illinois University. Although the American population is the focus of Miller's remarks, international comparisons in studies of scientific literacy indicate that they could apply with equal validity to populations in other developed countries (see chapter 7 in Science and Engineering Indicators 2010). 
with a significant dilemma in attempting to form judgements about complex public health problems when its cognitive resources for doing so are limited to a greater or lesser extent.

If public health science is to succeed in its mission of protecting the health of the public, some way must be found through this impasse. That way, I argue, lies in a new emphasis on the reasoning strategies that the public uses to assess public health issues. ${ }^{4}$ These strategies are unlikely to consist in deduction and induction, as certain knowledge and even inductive probabilities are often not available to the public health reasoner who must engage in judgement in the absence of knowledge. ${ }^{5}$ It is in a context of pervasive uncertainty and lack of knowledge that presumptive reasoning strategies come to the fore. These strategies are adapted to the uncertain conditions that attend public health reasoning. ${ }^{6}$ Specifically, it will be argued that a group of these strategies, which philosophers and logicians have traditionally characterized as informal fallacies, function as cognitive heuristics that guide reasoners through complex deliberations often in the absence of knowledge. These heuristics are a type of cognitive shortcut when full consideration of an issue is

4 I say "new emphasis" because, of course, reasoning has always been viewed as an indicator of scientific literacy (for discussion of work in this area, see "Reasoning and Understanding the Scientific Process" in chapter 7 of the Science and Engineering Indicators 2010). Similarly, reasoning has been identified as a key element in effective health communication within public health work: "Even if communication processes successfully identify where and how to reach vulnerable populations, the messages themselves must be compatible with the cultural orientations, information priorities, and reasoning strategies of affected populations" (Vaughan and Tinker, 2009: S329). Implicit in "new emphasis" is the suggestion that much of this focus has not produced beneficial outcomes. It is in an attempt to remedy this situation that the analysis of the present paper is being undertaken.

${ }^{5}$ In some cases, this absence of knowledge describes the epistemic situation of scientists, such as when scientists did not know if BSE would transmit to humans when the disease first emerged in British cattle in 1986. In other cases, this absence of knowledge captures the epistemic situation of the public, as when public health issues demand a level of knowledge and understanding that exceeds the cognitive grasp of the lay person. Irrespective of its source, a lack of knowledge demands a unique set of reasoning strategies that are quite unlike the traditionally dominant modes of deductive and inductive reasoning.

6 This adaptation is due in no small part to the epistemic concept of presumption that lies at the heart of these strategies. I have argued elsewhere that presumption is a neglected epistemic concept which has transformed the analysis of the informal fallacies. Specifically, certain features of presumptions, such as their defeasibility, their orientation to action and their low epistemic standing, have enabled these fallacies to function in a rational capacity at the outset of a scientific inquiry. For discussion of these features of presumption, the reader is referred to Cummings (2010). 
beyond the cognitive capacities of a reasoner or when a lack of knowledge threatens to undermine judgement. In both scenarios, these heuristics permit decision-making and judgement to proceed in a context where a demand for deduction or induction, and certain knowledge or probabilistic theses, would stall reasoning from the outset. Two such heuristics - the argument from ignorance and the argument from authority - are considered below and in Cummings (2014a). Two further heuristics, namely, circular argument and analogical argument, are examined in Cummings (2014b, 2014c). The same property is common to all these strategies, that is, their guidance of reasoning in adverse epistemic conditions. With this property in mind, we proceed to examine how ignorance and authority arguments operate in general and in a public health context in particular.

\section{Heuristics and public health reasoning}

The idea that heuristics play a role in reasoning is certainly not new. Reasoning heuristics were first systematically studied by Amos Tversky and Daniel Kahneman. In their landmark article "Judgment under Uncertainty: Heuristics and Biases," Tversky and Kahneman (1974: 1124) described a number of heuristics that reasoners use in probabilistic reasoning: "Many decisions are based on beliefs concerning the likelihood of uncertain events...people rely on a limited number of heuristic principles which reduce the complex tasks of assessing probabilities and predicting values to simpler judgmental operations." Although Tversky and Kahneman acknowledged that heuristics could be useful, they were concerned to emphasise the "severe and systematic errors" to which heuristics could lead. One such error is known as the gambler's fallacy, the belief that random processes self-correct: "if [a random] sequence has strayed from the population proportion, a corrective bias in the other direction is expected" (Tversky and Kahneman, 2004: 193).

By the time heuristics began to receive sustained attention in the literature on risk, an altogether more benign view of these cognitive operations was beginning to take shape. The emphasis now was less on the errors in reasoning to which heuristics might lead and more on their facilitative function in dealing with complex problems. Some of these problems concerned issues of public health significance. Trumbo (2002) and Johnson (2005) discussed heuristics in two studies that applied a heuristicsystematic model to the assessment of risk. These studies re-

(C) Louise Cummings. Informal Logic, Vol. 34, No.1 (2014), pp. 1-37. 
quired subjects to assess risks that were communicated in epidemiological information about cancer rates (Trumbo) and which were posed by a semi-hypothetical industrial facility (Johnson). Johnson (2005: 632) states that

[a]...heuristic-systematic model (HSM) separate[s] systematic from heuristic information processing. The systematic approach...is deliberative, attends to detail, weighs alternative views, and assesses argument quality in judging the validity of persuasive messages. The heuristic approach is alert to cues (e.g., trusted groups' evaluation of the information) and simple decision rules (if encoded in memory, accessible to recall, and deemed reliable) justifying quick intuitive judgment.

Wilson et al. (2004) examined heuristic processing in a study of how adults assessed risks associated with genetically modified food crops.

The first attempt to construe the informal fallacies as heuristics was undertaken by Walton (2010). According to Walton, many of the informal fallacies can be analyzed in terms of an argumentation scheme and corresponding parascheme. The argumentation scheme is part of a newer (in evolutionary terms) cognitive system that is slow, controlled and conscious. The person who reasons according to an argumentation scheme addresses critical questions that are aimed at exposing logical weaknesses in an argument, if such weaknesses exist. A parascheme is part of an older cognitive system that is fast and automatic and uses heuristics to jump to conclusions. These heuristics can result in successful solutions to problems, but may on occasion lead to error. Walton demonstrates the use of argumentation schemes and paraschemes in relation to a lack of evidence argument (the argumentum ad ignorantiam). The argumentation scheme for this fallacy contains critical questions, one of which addresses the depth of search of the relevant knowledge base. The parascheme represents the structure of the heuristic corresponding to this informal fallacy. This scheme bypasses critical questions and takes the reasoner from an ordinary premise of the form "A is not known to be true" to the conclusion "A is false" (Walton, 2010: 178).

So heuristics are not a new phenomenon in the study of reasoning or even the study of public health reasoning. But what is novel about the approach adopted in this paper is that no-one has previously attempted to characterize informal fallacies in terms of cognitive heuristics that people employ when they form judgements about public health problems. Yet, there is much to recommend this approach. For those philosophers and logicians 
who have subjected the informal fallacies to serious scrutiny, the rewards have been plentiful. Quite apart from being examples of weak, bad or shoddy reasoning, the informal fallacies have been found to be rationally warranted arguments within certain contexts of use. A sizeable literature now exists on non-fallacious variants of most of the major fallacies. ${ }^{7}$ An altogether smaller literature has sought to describe how these fallacies function non-fallaciously within the context of important public health issues (Cummings, 2002, 2004, 2009, 2010, 2011, 2012a, 2012b, 2012c, 2013, 2014d). What these latter studies have revealed is that these argument forms can sustain reasoning in contexts that preclude other modes of reasoning, principally deduction and induction. These contexts exhibit pervasive uncertainty of the type commonly encountered at the outset of a scientific inquiry or when deliberations exceed a reasoner's available cognitive resources. In the sections to follow, we examine the features of two such heuristics, the argument from ignorance and the argument from authority. The findings of a study that examines the conditions under which it is reasonable or rational for subjects to accept and reject these argument forms are reported (see Blair (2012) for discussion of reasonableness). This study extends empirical research into the fallacies that was recently initiated by van Eemeren et al. (2009) in their experimental studies of pragma-dialectical rules for a critical discussion. As well as making an original contribution to our knowledge of public health reasoning, this paper is thus also making a contribution to what is a rather small empirical literature on the informal fallacies.

\subsection{Argument from ignorance}

The argument from ignorance is a particularly productive reasoning strategy in contexts of uncertainty. The argument consists in arguing from a lack of knowledge that $\mathrm{P}$ is true (or false)

\footnotetext{
${ }^{7}$ The work of two fallacy theorists-Douglas Walton and John Woods-has been particularly influential in this regard. In a large number of books and journal articles, these theorists have described non-fallacious forms of petitio principii (begging the question), argumentum ad ignorantiam (the argument from ignorance), and argumentum ad baculum (the argument from the stick or appeal to force), amongst others (Walton 1985, 1992; Woods 1995, 2004). Of course, in emphasizing that there exist non-fallacious variants of the informal fallacies, this is not the same as saying that there are no such things as fallacious arguments. For discussion of novel fallacious arguments in the context of the BSE problem, the reader is referred to Cummings (2005).
} 
to the falsity (or truth) of $\mathrm{P}$ (where $\mathrm{P}$ is a proposition). Variants of the argument involve claims to the effect that there is no evidence or no (scientific) justification that $\mathrm{P}$ is true. The argument was used extensively by scientists and government ministers during the UK's BSE crisis, where its use was intended to reassure the public about the safety of beef for human consumption (Cummings, 2002, 2009, 2010, 2011, 2012a, 2012b, 2012c, 2013, 2014d):

There is no evidence that British beef is unsafe to eat. Therefore, British beef is not unsafe (i.e., is safe) to eat.

The argument from ignorance can be more or less warranted in different contexts of use. It is a particularly robust form of reasoning when two conditions are fulfilled: (1) the knowledge base on a certain topic or question is closed (i.e., there is epistemic closure of the base), and (2) the knowledge base has been exhaustively searched. Both these conditions were satisfied when scientists argued during the BSE epidemic that scrapie was not transmissible to humans on the grounds that there was no evidence that the disease was transmissible to humans (Cummings, 2010). In this case, the knowledge base on scrapie was closed. This disease had been endemic in the sheep population of Great Britain for some 250 years by the time BSE emerged and had also been extensively investigated by British scientists since the 1940s. Also, the knowledge base on scrapie had been extensively searched. A review of world literature by Brown et al. (1987) had established that there was no epidemiological evidence of a link between scrapie in sheep and Creutzfeldt-Jakob disease (CJD) in humans.

However, when scientists and others argued during the BSE crisis that BSE was not transmissible to humans on the grounds that there was no evidence that it was transmissible, an altogether less warranted argument from ignorance was in play. When BSE first emerged in British cattle in 1986, it was simply not possible to claim closure for the knowledge base on this disease. Experimental and other studies of the disease had yet to be undertaken. Moreover, BSE was known to be a transmissible spongiform encephalopathy (TSE), a group of animal and human diseases with lengthy incubation periods. To the extent that it could take many years before natural transmission of BSE might become apparent to investigators, the knowledge base on BSE could not be closed in 1986 or indeed for some time to come. The extent to which reasoners are able to identify when conditions (1) and (2) above are fulfilled in ignorance reasoning will be examined in section 3 . 
The argument from ignorance is a rationally warranted cognitive heuristic not just for scientists dealing with uncertainty when confronted with an emerging infectious disease like BSE, but also for the non-expert reasoner who must engage in judgement on an issue about which he lacks knowledge. The argument effectively transforms a negative epistemic situation (i.e., a lack of knowledge) into a positive epistemic situation in which a proposition has either been confirmed or disconfirmed (Cummings, 2002). It is this capacity to advance reasoning by transforming the absence of knowledge into a productive source of new claims (e.g., scrapie is not transmissible to humans) that confers heuristic value on this particular argument form (Cummings, 2002, 2010). It is this same capacity that found scientists, who investigated the emergence of BSE, using the argument to beneficial effect during scientific inquiry into this disease. Where a lack of knowledge threatened to stall inquiry, particularly in the early phase of inquiry when little was known about $\mathrm{BSE}$, the argument from ignorance enabled scientists to forge ahead on an exploratory basis until such times as sufficient evidence became available for deductively warranted conclusions to be drawn (Cummings, 2010). The heuristic value of this argument is not lost on the lay reasoner either, whose cognitive deliberations about public health problems are equally vulnerable to limitations resulting from a lack of knowledge of scientific issues. We will see in section 3 if lay reasoners are able to identify the conditions under which the argument from ignorance is functioning as an effective heuristic in public health reasoning.

\subsection{Argument from authority}

The argument from authority, also known as the argument from expertise or argumentum ad verecundiam, ${ }^{8}$ appeals to the expert or authority who produces a claim as grounds for the truth of that claim. ${ }^{9}$ For this argument to have rational legitimacy, the

\footnotetext{
8 Although "argumentum ad verecundiam" (literally, the argument from modesty) is often used to describe arguments that appeal to authority, Walton (1995: 278) remarks that this expression should be used only to refer to fallacious appeals to authority.

${ }^{9}$ Walton (1997: 258) uses the following argumentation scheme for appeals to expert opinion, in which $A$ is a proposition, $E$ is an expert and $D$ is a domain of knowledge: $E$ is an expert in domain $D$.

$E$ asserts that $A$ is known to be true.

$A$ is within $D$.

Therefore, $A$ may (plausibly) be taken to be true.
} 
so-called authority must have genuine as opposed to apparent expertise in an area (as indicated by professional standing and academic or other qualification) and must be motivated by scientific ideals such as objectivity and impartiality. The argument from authority is widely used in scientific reasoning in general and in public health reasoning in particular (see Cummings (2010) for an extensive discussion of the use of this argument during the BSE epidemic). It is not difficult to see why this is the case. The lay reasoner cannot possibly have knowledge of the various scientific disciplines to which public health problems relate. On the single issue of BSE, knowledge of - amongst other areas-human and animal TSEs, veterinary science, neuropathology, and zoonoses (human diseases with origins in lower vertebrates) was necessary to assess the implications of BSE for human health. No single expert could embody this vast range of knowledge, let alone members of the public. The argument from authority enables lay reasoners to defer to suitable authorities in forming judgements about public health issues. The heuristic value of this argument consists in the fact that the lay reasoner does not need to have direct knowledge of the disciplines to which an issue relates. ${ }^{10}$ Rather, he or she merely needs to accurately identify those factors that are indicative of genuine, impartial expertise, as this particular form of expertise is the basis of the most rationally warranted authority appeals. We will see in section 3 what factors are significant for lay reasoners in their assessments of different types of expertise.

Commentators have acknowledged the need for authority appeals or appeals to expertise in scientific and public health contexts. The Science and Engineering Indicators 2010 state that

${ }^{10}$ In fact, the argument from authority functions by bypassing knowledge of disciplines. The lay reasoner is effectively spared the need to engage with disciplines, the key feature of which is that they are beyond one's grasp on account of their complexity. Willard (1990: 11) captures this point as follows:

I might prefer the Darwinian to the biblical narrative because I have examined the fossil record for myself, worked through the details of Darwin's argumentation, and followed the debates that led up to the present version of the theory; or, failing to one degree or another at any or all of these tasks, I prefer the Darwinian narrative because I accept the conclusions of experts. That is, given the numbers and enormity of technical literatures, and the complexities within them, I accept expert testimony in lieu of inspecting evidence or hearing the arguments out (italics in original). 
[f]or the science-related decisions that citizens face, a comprehensive understanding of the relevant scientific research would require mastery and evaluation of a great deal of evidence. In addition to relying on direct evidence from scientific studies, citizens who want to draw on scientific evidence must consult the judgments of leaders and other experts whom they believe can speak authoritatively about the scientific knowledge that is relevant to an issue (National Science Board, 2010: 7-31).

Some investigators have also remarked on the heuristic nature of authority appeals. In a study that examined subjects' perception of cancer rates, Trumbo (2002: 368) stated that "[h]euristic processing...occurs when individuals use simple decision rules to help them arrive at a judgment about message validity. Such decision rules might manifest themselves as agreement with expert opinion or a tendency to agree with consensus" (italics added). However, while investigators acknowledge the heuristic value of authority appeals, there is rather less clarity on how to examine such appeals in actual lay reasoners. Empirical studies have typically examined expertise as one dimension of trust, a topic on which there exists a substantial literature. ${ }^{11}$ One study in particular confirms the idea that a lack of knowledge is the impetus for authority appeals, in that public reliance on trust is shown to be related to lack of knowledge of a perceived hazard on the part of subjects. ${ }^{12}$ But what this research lacks is any sense of expertise in its own right (apart from a wider concept of trust) and how this altogether narrower notion shapes the reasoning processes

\footnotetext{
11 Discussion of trust in the literature on risk tends to take one of two forms. Some investigators identify multiple dimensions to the trust concept. Berry (2004: 21) captures this approach when she states that "[r]esearch has shown that trust is multifaceted rather than one-dimensional, with relevant factors including perceived competence, objectivity, fairness and consistency." Other investigators argue that the different attributes associated with trust can be adequately captured within two main dimensions to the concept. This alternative approach is characterised by Frewer et al. (1996: 474) when they remark that "two major dimensions have emerged as being important in determining trust - that of 'competence', the expertise held by the communicator, and the extent to which they are able to pass on information about a particular subject area and 'trustworthiness', the degree to which the communicator will be truthful in the information communicated." For discussion of how different investigators characterize trust, the reader is referred to Poortinga and Pidgeon (2003).

12 Siegrist and Cvetkovich (2000: 713) state that their "results suggest that the lay public relies on social trust when making judgments of risks and benefits when personal knowledge about a hazard is lacking."
} 
to which the public subscribes. This omission will be the focus of the authority appeals examined in the next section.

\section{A study of two informal fallacies}

\section{Rationale}

This study is an experimental investigation ${ }^{13}$ of the informal fallacies, a branch of inquiry that has been the exclusive domain to date of logic and philosophy. It is also the first attempt to examine how the public reasons using these argument forms in a public health context. The aim of this study is to establish the conditions under which subjects judge arguments from ignorance and from authority to be rationally warranted during deliberation on public health problems. These problems are characterized by a high degree of scientific knowledge which lay reasoners lack and which they cannot acquire on account of cognitive and educational limitations. Both argument forms are thus serving as cognitive heuristics that facilitate the public's reasoning about these problems in the absence of knowledge.

The philosophical literature on these fallacies suggests that the argument from ignorance is more or less warranted in accordance with two factors: (1) the closure of the knowledge base on a topic or question, and (2) a search of the knowledge base to which the topic or question relates. These epistemic features of the argument from ignorance are the basis for varying the following conditions in the study: closure (full versus incomplete) and search (exhaustive versus limited). If philosophers are correct about the rational merits of this particular argument form, it

\footnotetext{
${ }^{13}$ When one thinks of experimental investigations of reasoning, the work of cognitive psychologists such as Phillip Johnson-Laird on deductive reasoning typically comes to mind. While this study shares certain features with this work - the presentation of stimulus material that tests if certain inferences have been drawn by subjects-it also differs from this work in significant ways. For example, studies of deductive reasoning present information in the form of premises in a structured argument to subjects, who are then required to draw a conclusion or judge the validity of a presented conclusion. In the current study, reasoning is examined in a discursive context with subjects asked to justify their assessment of the reasoning of certain scientific actors. To this extent, this study is more akin to the experimental reasoning studies of David N. Perkins, who has studied how subjects reason about everyday issues which are often polemical in nature (e.g., whether or not a military draft in the United States would increase American influence in the world). It is worth noting that Finocchiaro (1994: 14) has remarked of Perkins's approach that it is "much more valid than the usual experiments and provides the only effective experimental means of getting in touch and coming to grips with the phenomenon of reasoning."
} 
is to be expected that subjects will accept more ignorance arguments when there is full closure of a knowledge base that has been exhaustively searched, and will accept progressively fewer of these arguments as the knowledge base approaches an incomplete state and has only been searched in a limited way. To control for the fact that the judgements of subjects will be influenced by their prior beliefs about the topics addressed in the scenarios, ${ }^{14}$ an equal number of actual and non-actual situations are depicted. The eight scenarios addressed (1) the transmissibility of scrapie to humans, (2) trials of a new asthma drug, (3) the transmissibility of BSE to humans, (4) chemicals in effluent from a pharmaceutical plant, (5) the safety of genetically modified foods, (6) a food additive in dairy products, (7) the swine flu immunization, and (8) an outbreak of severe food poisoning. The types of ignorance arguments investigated in the study are shown in Appendix 1.

Philosophical reflection on the argument from authority is also the basis for the different types of authority appeals that are included in the study. To the extent that authority appeals are rationally warranted when the expertise of the authority is genuine as opposed to dubious in nature, and when expertise upholds the ideal of scientific objectivity (i.e., is impartial as opposed to partial), there is justification for the following conditions in the study: expertise (genuine versus dubious) and expertise (partial versus impartial). It is to be expected that as authority appeals move progressively away from the condition in which expertise is genuine and impartial that subjects will be increasingly inclined not to accept these appeals (i.e., they will not find them valid or warranted). As with ignorance arguments, it is important to control for the fact that subjects' judgements may be influenced by prior beliefs that they have about certain public health topics or issues. To this end, an equal number of actual and non-actual scenarios are included. The eight scenarios used to examine authority appeals are (1) pronouncements on BSE by the Spongiform Encephalopathy Advisory Committee, (2) use of chemicals in food production, (3) aspirin use and Reye's syn-

\footnotetext{
${ }^{14}$ It is expected that background knowledge and beliefs will affect the information that subjects attend to in the passages and the significance that subjects attach to this information. As Klahr (2000: 30) remarks: "When people are reasoning about real world contexts, their prior knowledge imposes strong theoretical biases.... These biases influence not only the initial strength with which hypotheses are held-and hence the amount of disconfirming evidence necessary to refute them-but also the features in the evidence that will be attended to and encoded."
} 
drome, (4) cancer risks posed by a nuclear power facility, (5) safety of the measles, mumps, rubella (MMR) vaccine, (6) electromagnetic emissions from mobile phone masts, (7) pronouncements on BSE by the Southwood Working Party, and (8) air-borne chemical emissions from a recycling facility. The types of authority appeals included in the study are shown in Appendix 2. In summary, the two hypotheses to be tested in this study can be stated as follows:

Hypothesis 1: It is predicted that subjects will assess the rational warrant of the argument from ignorance on the basis of two epistemic criteria: (1) closure of a knowledge base and (2) search of a knowledge base. It is expected that subjects will judge arguments from ignorance that satisfy these criteria to be rationally warranted while arguments which fall short of these criteria will be judged to be rationally unacceptable.

Hypothesis 2: It is predicted that subjects will assess the rational warrant of the argument from authority on the basis of two epistemic criteria that reflect (1) how genuine an authority's expertise is and (2) how impartial an authority's expertise is. It is expected that subjects will judge arguments from authority that satisfy these criteria to be rationally warranted while arguments which fall short of these criteria will be judged to be rationally unacceptable.

\section{Method}

This study is part of a wider investigation of the role in public health reasoning of four informal fallacies (ignorance argument, authority argument, circular argument and analogical argument). Each subject was presented with eight public health scenarios in the form of a written, postal questionnaire. There were three different versions of the questionnaire and each respondent completed only one version. Scenarios examining the four fallacies were randomly distributed across the three versions of the questionnaire. The scenarios consisted of a single paragraph of information following which were four questions. Two of the questions required either a yes/no response or a response of a few words, and could be answered on the basis of information explicitly presented in the corresponding passage. These questions were intended to give respondents the impression that they were engaging in a reading comprehension task. A third question was intended to establish if subjects had derived a particular ignorance inference. Depending on the passage, a "yes" or "no" response indicated that respondents had derived the target igno- 
rance inference. A response of "don't know" indicated that subjects had failed to derive the target inference. A fourth question asked subjects to explain their answer to the inference question. It was intended to elicit an open response from which information could be gleaned about the factors that had been significant in the individual subject's reasoning. The following passage and questions examined an ignorance inference with the features $<$ full closure + exhaustive search + actual scenario $>$ :

Scrapie in sheep and BSE in cattle belong to the same family of diseases, the transmissible spongiform encephalopathies (TSEs). These diseases are caused by an unconventional pathogen (an infectious protein called a prion) and are invariably fatal in the animals and humans that develop them. When BSE first emerged in British cattle in 1986, scrapie had been present in British sheep for over 250 years. Scrapie has been the subject of extensive scientific study since the 1940s. Numerous epidemiological studies from around the world have investigated if there is a link between scrapie and a TSE in humans called Creutzfeldt-Jakob disease (CJD). In 1987, Brown and colleagues conducted a review of all these studies and found that there was no evidence that scrapie was transmissible to humans.

(1) Is Creutzfeldt-Jakob disease a TSE in humans?

(2) Is scrapie transmissible to humans?

Yes No Don't know

(3) When did the scientific study of scrapie first begin?

(4) Please explain your response to (2).

Authority arguments were assessed using a similar format. As with ignorance arguments, four questions followed each passage. Two of these questions examined information presented in the passage and required either a yes/no response or a minimal response of just a few words. The question targeting the authority argument in the passage asked subjects to rate the conclusions or pronouncements of an individual scientist, scientific committee or scientific review panel as valid, moderately valid or not valid at all. A fourth question asked subjects to explain their response to the authority question. The open-ended nature of the response was intended to reveal the types of factors to which subjects attached significance in rating an authority argument. 
The following passage and questions examined an authority argument with the features <genuine expertise + partial expertise + actual scenario $>$ :

Reye's syndrome is a serious illness that can affect all organs in the body but most often the brain and liver. The condition kills one in three children who develop it. In 1980, in response to a number of studies which revealed that children with chicken pox or flu who took aspirin were more likely to develop Reye's syndrome, the Centers for Disease Control (CDC) in the US issued an alert to the medical community. The aspirin industry challenged the causal association between aspirin and Reye's syndrome which had been revealed by the studies and which had been the basis of the CDC's actions. Several pharmaceutical companies that manufacture aspirin collaborated on the establishment of a scientific review panel to consider all the available evidence in relation to aspirin and Reye's syndrome. The panel consisted of leading American and British experts in pharmacoepidemiology, the discipline that studies the effects of drugs on populations. The review panel concluded that there was insufficient evidence to indicate that aspirin caused Reye's syndrome in children. Each of the experts on the review panel received a consultancy fee from the pharmaceutical companies that manufacture aspirin.

(1) Which two organs are most often affected by Reye's syndrome?

(2) How do you rate the conclusions reached by the scientific review panel?

Valid Moderately valid Not valid at all

(3) Please explain your response to (2).

(4) Did the review panel contain experts in pharmacoepidemiology?

All responses were written on the questionnaire which was completed anonymously. Subjects were informed that the task would take approximately 30 minutes to complete and that all data and responses were confidential. They were advised to undertake the exercise in a distraction-free environment and not to consult sources such as books and the internet, as questions were intended to elicit judgements from subjects rather than correct answers. A deadline for return of the questionnaire was commu- 
nicated to all subjects. At the outset of the study, all scenarios were examined by two public health consultants and two academic linguists. This was done with a view to establishing, respectively, the plausibility (in public health terms) of the scenarios and the comprehensibility of the linguistic constructions used to characterize them.

\section{Subjects}

A total of 879 subjects participated in the study. All subjects were between 18 and 65 years of age. Subjects could be male or female, of any ethnic or socioeconomic background and could be educated to either university level or secondary school level. The characteristics of all respondents to the questionnaire are shown in Appendix 3. The three versions of the questionnaire received the same number of respondents: version A (293 subjects), version B (293 subjects), version C (293 subjects). Subjects were recruited to the study through a combination of methods. For the most part, the participation of subjects was secured through a series of formal recruitment activities which were undertaken in several venues, including public areas in local hospitals, staff dining facilities in large retail outlets and the lounge areas of private health clubs. A smaller number of subjects were recruited through a technique known as snowball sampling. In this technique, respondents to the questionnaire either offered to provide, or were asked to provide, the contact details of other individuals who might be willing to participate in the study. Questionnaires were subsequently sent to these individuals, some of whom recommended, in turn, other people who could participate in the investigation. ${ }^{15}$ Snowball sampling is a particularly effective way of recruiting subjects for a study when target groups are known to be inaccessible for a range of reasons (Browne, 2005). It was predicted at the outset of the study that secondary school educated males would be particularly unwill-

15

A sampling procedure may be defined as snowball sampling when the researcher accesses informants through contact information that is provided by other informants. This process is, by necessity, repetitive: informants refer the researcher to other informants, who are contacted by the researcher and then refer her or him to yet other informants, and so on. Hence the evolving 'snowball' effect, captured in a metaphor that touches on the central quality of this sampling procedure: its accumulative (diachronic and dynamic) dimension' (Noy, 2008: 330).

(C) Louise Cummings. Informal Logic, Vol. 34, No.1 (2014), pp. 1-37. 
ing to participate in an investigation of this type. ${ }^{16}$ Despite considerable efforts to recruit these subjects, the final recruitment figures revealed that secondary school educated males did indeed constitute an underrepresented group in the study: secondary school males (87 subjects), secondary school females (203 subjects), university males (205 subjects), university females (384 subjects).

\section{Results}

Full results for the argument from ignorance and the argument from authority are displayed in Appendices 1 and 2, respectively. Results for both types of argument are presented in this section.

Acceptance rates for argument from ignorance inferences decreased as closure and search conditions were progressively manipulated in a negative direction, that is, towards incomplete closure and limited search: $71.4 \%$ (full closure, exhaustive search), 33\% (full closure, limited search), 16.6\% (incomplete closure, exhaustive search), and $10.3 \%$ (incomplete closure, limited search). The rate of inference rejection decreased as closure and search conditions were progressively manipulated in a positive direction, that is, towards full closure and exhaustive search: $89.7 \%$ (incomplete closure, limited search), $83.4 \%$ (incomplete closure, exhaustive search), 67\% (full closure, limited search), and $28.6 \%$ (full closure, exhaustive search). There was a negligible difference in inference acceptance rates between actual and non-actual scenarios under some epistemic conditions such as $<$ full closure, exhaustive search>: $71.4 \%$ (actual scenario) and $68.4 \%$ (non-actual scenario). Differences were more pronounced under other epistemic conditions such as <full closure, limited search>: $17.6 \%$ (actual scenario) and 33\% (non-actual scenario). Some of these differences were found to be statistically significant and will be addressed in the discussion section.

Data were analyzed using the Statistical Package for the Social Sciences (SPSS for Windows Version 18.0). In a number of cases, Pearson chi-square values supported initial impressions

\footnotetext{
${ }^{16}$ Level of formal education is almost certainly a key factor in the poor engagement of secondary school males in this study. However, another factor is likely to be the topic of the study. There is evidence that biological and health sciences are of less interest to men than the physical sciences. As a healthrelated discipline, public health science may simply not engage the interest of men sufficiently for them to want to engage in this study. See chapter 7 in the Science and Engineering Indicators 2010 (National Science Board, 2010) for a detailed discussion of the role of formal education and sex in both interest in science and performance in surveys of scientific literacy.
} 
of large and potentially significant differences between percentage results and, similarly, of small and negligible differences between percentage results. In this way, small percentage differences between the epistemic conditions < full closure, exhaustive search, actual scenario> and <full closure, exhaustive search, non-actual scenario > were obtained. These included inference acceptance rates of $71.4 \%$ (actual scenario) and $68.4 \%$ (nonactual scenario), and inference rejection rates of $28.6 \%$ (actual scenario) and $31.6 \%$ (non-actual scenario). These small and negligible percentage differences were confirmed by a large Pearson chi-square value of 58.097. This value exceeds 0.05 , indicating that there was no significant difference between the <actual> and <non-actual> variables examined in these respective passages.

However, there were also some large and, as it emerged, statistically significant differences in the inference acceptance and rejection rates across the passages that examined the argument from ignorance. For example, under the epistemic conditions <full closure, exhaustive search, non-actual scenario>, $68.4 \%$ of subjects accepted the ignorance inference while only $10.3 \%$ did so under the epistemic conditions <incomplete closure, limited search, non-actual scenario $>$. This large percentage difference was statistically significant with a Pearson chi-square value of 0.027 indicating that the null hypothesis must be rejected, i.e., the difference between these variables was not the result of chance. In total, four statistically significant differences were obtained for the argument from ignorance passages. These passages and their Pearson chi-square values are displayed below:

\begin{tabular}{|l|c|c|}
\hline \multicolumn{1}{|c|}{ Passage comparison } & $\begin{array}{c}\text { Chi-square } \\
\text { value }\end{array}$ & Significance \\
\hline $\begin{array}{l}\text { Incomplete, exhaustive, actual } \\
\text { compared to } \\
\text { Full, limited, actual }\end{array}$ & 0.00 & $<0.05$, significant \\
\hline $\begin{array}{l}\text { Full, exhaustive, non-actual } \\
\text { compared to } \\
\text { Incomplete, limited, non-actual }\end{array}$ & 0.027 & $<0.05$, significant \\
\hline $\begin{array}{l}\text { Incomplete, limited, actual } \\
\text { compared to } \\
\text { Full, limited, non-actual }\end{array}$ & 0.029 & $<0.05$, significant \\
\hline
\end{tabular}

(C) Louise Cummings. Informal Logic, Vol. 34, No.1 (2014), pp. 1-37. 


\begin{tabular}{|l|l|l|}
\hline $\begin{array}{l}\text { Incomplete, exhaustive, non- } \\
\text { actual } \\
\text { compared to } \\
\text { Incomplete, limited, non-actual }\end{array}$ & 0.022 & $<0.05$, significant \\
\hline
\end{tabular}

Table 1

It is worth remarking that two other comparisons of argument from ignorance passages resulted in chi-square values that approached significance. These comparisons were (1) <incomplete closure, exhaustive search, non-actual scenario $\rangle$ and $\langle$ incomplete closure, limited search, actual scenario> (chi-square value $=0.069$ ), and (2) <full closure, limited search, actual scenario> and <incomplete closure, limited search, actual scenario> (chi-square value $=0.068$ )

Potentially significant trends were also observed for the argument from authority. As expertise was progressively manipulated in a negative direction, that is, towards expertise that was increasingly dubious and partial in nature, the percentage of respondents who rated authority inferences as valid steadily declined: $65.7 \%$ (genuine, impartial expertise), 21.5\% (dubious, impartial expertise), $12.1 \%$ (genuine, partial expertise), and $3.4 \%$ (dubious, partial expertise). As expertise was progressively manipulated in a positive direction, that is, towards expertise that was increasingly genuine and impartial in nature, the percentage of respondents who rated authority inferences as not valid at all steadily declined: $69.6 \%$ (dubious, partial expertise), $62 \%$ (genuine, partial expertise), 24\% (dubious, impartial expertise), and 6.3\% (genuine, impartial expertise). There was a negligible difference in the percentage of respondents who rated authority inferences as valid under some epistemic conditions such as <dubious, partial expertise>: $3.8 \%$ (actual scenario) and $3.4 \%$ (non-actual scenario). Differences were more marked under other epistemic conditions such as <dubious, impartial expertise >: $21.5 \%$ (actual scenario) and 6.2\% (non-actual scenario). Some of these differences were statistically significant and will be addressed in the discussion section.

Statistical analysis also confirmed initial impressions of small and negligible differences in subject responses to some authority passages, and larger and potentially significant differences in responses to other authority passages. In this way, there were negligible differences in the percentage of subjects who rated authority inferences as valid and not valid at all under the conditions <genuine, impartial expertise, actual scenario> and <genuine, impartial expertise, non-actual scenario>. For example, the percentage of subjects who rated passages under these conditions as valid was $65.7 \%$ (actual scenario) and $57.1 \%$ (nonactual scenario), while the percentage who rated these passages as not valid at all was $6.3 \%$ (actual scenario) and 9.9\% (non- 
actual scenario). Statistical analysis confirmed that these small percentage differences were non-significant. A Pearson chisquare value of 15.694 for these passages exceeds 0.05 , indicating that there was no significant difference in the <actual> and $<$ non-actual $>$ variables, at least as examined under the epistemic conditions <genuine, impartial expertise>.

However, there were also some large and, as it emerged, statistically significant differences in subjects' validity ratings across the passages that examined the argument from authority. For example, under the epistemic conditions <genuine, partial expertise; actual scenario>, only $38 \%$ of subjects rated the inference as either valid or moderately valid while $64.1 \%$ did so under the epistemic conditions <genuine, partial expertise; nonactual scenario>. This large percentage difference was statistically significant with a Pearson chi-square value of 0.012 indicating that the null hypothesis must be rejected, i.e., the difference between these variables was not the result of chance. In total, three statistically significant differences were obtained for the argument from authority passages. These passages and their Pearson chi-square values are displayed below:

\begin{tabular}{|l|c|c|}
\hline \multicolumn{1}{|c|}{ Passage comparison } & $\begin{array}{c}\text { Chi-square } \\
\text { Value }\end{array}$ & Significance \\
\hline $\begin{array}{l}\text { Genuine, partial, actual } \\
\text { compared to } \\
\text { Genuine, partial, non-actual }\end{array}$ & 0.012 & $<0.05$, significant \\
\hline $\begin{array}{l}\text { Genuine, impartial, actual } \\
\text { compared to } \\
\text { Dubious, impartial, non-actual }\end{array}$ & 0.042 & $<0.05$, significant \\
\hline $\begin{array}{l}\text { Genuine, impartial, actual } \\
\text { compared to } \\
\text { Genuine, partial, non-actual }\end{array}$ & 0.049 & $<0.05$, significant \\
\hline
\end{tabular}

Table 2

It is worth remarking that one other argument from authority passage comparison resulted in a chi-square value that approached significance. This comparison was <genuine, partial expertise; actual scenario> and <dubious, partial expertise; actual scenario $>$ (chi-square value $=0.060$ ).

A subset of data underwent statistical analysis using the Pearson chi-square test in order to establish if there were any effects of respondents' gender and education level on reasoning. No significant differences were found on any of the passages in accordance with the gender and education level of respondents. 
This confirms in part a finding of Trumbo (2002) that the age and gender of participants did not have any effect on the type of information processing (systematic versus heuristic) that was used during the assessment of epidemiological information about cancer rates. Given this lack of significant differences, and the fact that attributes such as the age, gender and education level of subjects are not central to the questions investigated in this study, it was decided not to pursue further statistical analysis of these variables.

\section{Discussion}

This study contributes to empirical research in argumentation theory. Like the experimental studies of Van Eemeren et al. (2009), which reveal that people are able to judge the reasonableness of pragma-dialectical discussion rules, this investigation demonstrates that subjects are sensitive to the epistemic and logical conditions under which arguments from ignorance and authority are rationally warranted. Moreover, subjects' knowledge of these conditions comes into effect during reasoning about complex public health issues. A key feature of these issues is that lay people must form judgements about them in the absence of scientific knowledge and understanding. In terms of the argument from ignorance, subjects viewed these arguments as having greater rational warrant as epistemic conditions steadily approached the full closure and exhaustive search of a knowledge base. Conversely, subjects viewed these arguments as having less rational warrant as epistemic conditions steadily approached a state in which there was incomplete closure and a limited search of a knowledge base. These clear trends in the judgements of subjects are illustrated below, with figures indicating inference acceptance for the argument from ignorance (the <actual/non-actual> variable is omitted):

\section{maximum}
ference
Warrant (3) Incomplete closure, exhaustive search: $16.6 \%$ accept inference
(4) Incomplete closure, limited search: $10.3 \%$ accept inference
minimum 
Furthermore, these trends in subjects' judgements were supported by significant Pearson chi-square results, which indicate that differences in the response rates of subjects cannot be attributed to chance. Not only was there a significant difference in subjects' responses to passages representing conditions (1) and (4) - a finding which would be expected given the very different epistemic conditions contained in these passages-but there were also significant differences in responses to passages representing the conditions in (2) and (3), and (3) and (4). These latter findings suggest that subjects are able to recognize finegrained, subtle distinctions in epistemic conditions as well as the more pronounced epistemic and logical distinctions represented by the conditions in (1) and (4).

That subjects are sensitive to the logical and epistemic conditions under which the argument from ignorance is rationally warranted, is also suggested by a qualitative analysis of their extended responses in the questionnaires. Among responses which justify the acceptance of an inference in the conditions represented in (1) above were comments relating to the extent of the closure and search of a knowledge base. For example, subjects tended towards inference acceptance when scientists were represented as conducting extensive tests in an area (full closure of a knowledge base) and as reviewing all the evidence in an area (exhaustive search of a knowledge base):

\section{Full closure:}

clinical trials have been 'extensive' on a wide range of human subjects [...] would give a reasonable result (White male, 30 years old, university educated)

seems to have undergone extensive trials and tests (White female, 64 years old, secondary school educated)

\section{Exhaustive search:}

it has been reviewed by a panel of experts who have found it is not unsafe (White female, 31 years old, university educated)

Subjects were equally clear about the conditions which led them to reject the conclusions of arguments from ignorance. In this way, when considering passages which represented the epistemic conditions in (4) above, subjects made reference to specific factors which precluded the complete closure and exhaustive search of a knowledge base in an area. Such factors may be the lengthy incubation period of a disease like BSE or insufficient 
tests on a chemical, both of which appeared to preclude the closure of a knowledge base for subjects. Subjects were similarly disinclined to accept ignorance inferences when scientists produced statements about risk in the absence of a full scientific review of the evidence (that is, when there was a limited search of the knowledge base):

\section{Incomplete closure:}

if the incubation period is so long it is impossible to know either way at this stage (White female, 31 years old, university educated)

There have not been enough tests done to decide whether or not the "said" chemical is carcinogenic (White male, 50 years old, secondary school educated)

\section{Limited search:}

the scientist claimed there was no evidence to suggest a link between the chemical and cancer. Here it would be necessary to look at literature or actual laboratory tests to confirm whether it is carcinogenic or not (Pakistani Asian female, 26 years old, university educated)

Subjects were equally adept at recognizing the epistemic conditions under which arguments from authority are more or less rationally warranted. As conditions increasingly approached a situation in which expertise was judged to be genuine and impartial in nature, the number of subjects who rated authority inferences as valid steadily increased. As conditions approached a situation in which expertise was judged to be dubious and partial in nature, the number of subjects who rated authority inferences as valid or moderately valid steadily decreased. These trends in the responses of subjects can be seen below, with the figures indicating the percentage of subjects who rated authority inferences as valid or moderately valid under each set of epistemic conditions (the <actual/non-actual> variable has been omitted):

\section{maximum}
(1) Genuine, impartial expertise:
$93.7 \%$ valid/moderately valid
Rational
(2) Genuine, partial expertise: $64.1 \%$ valid/moderately valid
Warrant
(3) Dubious, impartial expertise: $48.1 \%$ valid/moderately valid
(4) Dubious, partial expertise: $30.4 \%$ valid/moderately valid minimum 
These trends were further supported by significant Pearson chi-square values. Subjects displayed an ability to distinguish between conditions in which scientific authorities displayed genuine as opposed to dubious expertise, with a significant chisquare value obtained for a comparison between two passages that represent the epistemic conditions in (1) and (3) above. However, subjects were equally adept at distinguishing between partial and impartial expertise on the part of scientists. This is confirmed by a significant chi-square value for a comparison between two passages that represent the epistemic conditions in (1) and (2) above.

Unlike the argument from ignorance, a significant chisquare value was also obtained for two argument from authority passages which differed in the <actual/non-actual> variable. These passages examined the development of Reye's syndrome in children as a result of taking aspirin (actual scenario) and a possible link between the development of a cancer called multiple myeloma and residency in the vicinity of a nuclear facility. Subjects were significantly less likely to rate the pronouncements of scientists as valid or moderately valid in the case of Reye's syndrome than they were in the case of the nuclear power facility. One possible explanation of this finding is that subjects operate with a higher standard of rational warrant - that is, they are less likely to accept scientific verdicts as valid - when there is a perceived health risk to children (Reye's syndrome) as opposed to "local residents," the latter including adults as well (nuclear power facility). An alternative explanation could be that the (almost exclusively) British subjects in this study were more likely to rate the verdicts of British scientists in the nuclear power facility scenario as being valid or moderately valid than they were the verdicts of American scientists in the Reye's syndrome scenario. This could reflect an increased level of trust in British scientists by British subjects. Whatever factor or factors were influential in subjects' ratings of scientific authorities in these particular scenarios, it is further evidence that background knowledge and beliefs play a significant role in the reasoning of subjects.

A qualitative analysis of the extended responses that subjects advanced in justification of their validity ratings revealed a number of "markers" of genuine expertise. These markers included the extensive knowledge and learning of scientists, their academic and professional qualifications, affiliation with reputable British or American universities, extensive experience in a 
scientific field, an outstanding record of publication in international journals and a high professional standing among colleagues in a field. There was an equally rich array of markers of scientific impartiality among the subjects' responses. They included freedom from political interference (e.g., politicians, policy makers), independence of commercial groups (e.g., farming industry, pharmaceutical companies) and independent, transparent funding of scientific research. Several of these issues are reflected in the comments from subjects which are presented below:

\section{Genuine expertise:}

They are experts providing a professional opinion within an area that they have knowledge and understanding of (White male, 35 years old, university educated)

The experts were leading figures in their fields of specialisation (White female, 41 years old, university educated)

The fact of previous BNF [British Nuclear Fuels] funding for all the scientists might cause sceptical eyebrows to be raised, but the national/international standing of the scientists concerned should mean that the report was a reasonable (valid) one in the light of the evidence available (White male, 62 years old, university educated)

\section{Impartial expertise:}

the experts were from academic institutes so independent from policy makers (White male, 25 years old, university educated)

The scientists were independent experts in no way linked to the food industry. There would be no bias to influence their assessment of safety (White female, 59 years old, university educated)

Even as subjects rated the opinions of scientists as valid or moderately valid, many sounded notes of caution and criticism. For example, a number of subjects went against the grain in describing a lack of industry funding as leading to poorer science and research through the loss of 'real' experts in a field. Other subjects drilled down into the expertise of individual scientists, challenging the scope and relevance of a particular scientist's expertise:

\section{Cautionary and critical comments:}

It's difficult to know how valid it is. For one thing scientists who received funding from the food industry/acted 
as consultants were not permitted to sit on the body. But this could have been a negative as they might have had the best advice and expertise on the subject (White female, 37 years old, university educated)

Leading experts and independent figures, but I'd want further details on the expertise of those involvedAlmond [a scientist named in the passage] ticks the "virology" and "immunology" boxes, but his school suggests his expertise may relate to animals, rather than humans (White female, 32 years old, university educated)

Some of the most stridently expressed comments in the questionnaires were made in relation to passages that threw into doubt the expertise of scientists. There were numerous markers of dubious expertise amongst subjects' responses. They included a lack of knowledge, training and specialisation on the part of scientists, the use of methodologically questionable techniques and procedures in scientific research and concerns about the scope and relevance of a scientist's expertise:

\section{Dubious expertise:}

I don't feel that he would be knowledgeable enough about diseases when his area of specialism is surgery (White female, 31 years old, university educated)

His speciality is surgery and transplants. Where is connection to MMR [measles, mumps, rubella vaccination]? (Indian Asian female, 32 years old, university educated)

He only conducted tests on 12 children - a very low number. Surely he could not make valid claims based on such a low number of cases? (White female, 37 years old, university educated)

Subjects were particularly forthright in expressing when they believed scientists' opinions were partial in some respect. Markers of partial expertise included comments to the effect that scientists were "in the pockets" or "on the payroll" of pharmaceutical companies and that they were "industry stooges." These commercial interests were characterized as compromising the objectivity of scientific research, with scientific judgements described as being 'swayed' or otherwise tainted by the fees scientists received for their work:

Partial expertise: 
The experts were on the payroll of the pharmaceutical companies...that is not ethical and de-legitimises the work done (White and Asian male, 28 years old, university educated)

Were they in the pockets of the pharmaceutical companies? (White female, 64 years old, secondary school educated)

there are obviously questions of bias here and whether the scientists were in effect industry stooges (White male, 46 years old, university educated)

Would their conclusions have been swayed by the fact too that they were receiving a consultancy fee from the pharmaceutical companies that manufacture aspirin? (White female, 41 years old, university educated)

These combined findings reveal a somewhat unexplored, and certainly untested, rational competence on the part of lay people during reasoning about complex scientific issues of the type encountered in public health. In the absence of scientific knowledge, lay people must find some means of coming to judgement about public health problems. Suspension of judgement certainly avoids the risk of error. But a policy of cognitive inaction presents other, potentially serious risks, when the consequence of this inaction is that protective public health measures are ignored or shunned. When lay people are confronted with gaps in their knowledge, arguments of the type investigated in this study function as quick 'rules of thumb' or, more formally, cognitive heuristics for bridging these gaps. It is under conditions of uncertainty that arguments from ignorance and authority leave their historical (and largely unfavourable) baggage behind and display their true value as effective strategies for charting a course to judgement in the absence of scientific knowledge. The fact that subjects appear to be so adept at recognizing the conditions under which these arguments are more or less rationally warranted is a reasonably strong basis for the conclusion that the epistemic distinctions explored in this study have psychological reality for lay people. At least this much is suggested by the findings of this experimental investigation of the informal fallacies.

The question arises of how these findings relate to theoretical frameworks of heuristic processing. Although such frameworks exist in public health - see studies of heuristic processing in risk assessment by Trumbo (2002) and Johnson (2005) in section 2 - none are able to capture the specific emphasis on informal fallacies in the approach examined in this paper. Recent 
work by Walton (2010) does, however, examine the relationship between informal fallacies and heuristics. Walton's characterization of the informal fallacies as heuristics was introduced briefly in section 2. His framework has a number of merits in terms of the approach to the fallacies taken in this paper. It is an explicit attempt to characterize the fallacies in cognitive terms. A cognitive approach to fallacy analysis has been woefully lacking in the informal logic and argumentation literature. ${ }^{17}$ Yet, such a cognitive reorientation of the fallacies seems to be a sine qua non of any account of the fallacies which construes them in terms of cognitive heuristics in public health reasoning. A further merit of Walton's approach is that it retains a strong normative character, notwithstanding its cognitive orientation. In this way, heuristics corresponding to informal fallacies are rationally (un)warranted given the rational standing of certain assumptions and exceptions (the latter form the "critical questions" of the associated argumentation scheme): "To judge whether an alleged argument from ignorance is fallacious the heuristic has to be examined in relation to whether other assumptions and exceptions need to be taken into account that may be acceptable or not" (Walton, 2010: 178).

Yet, certain drawbacks also attend Walton's framework. One drawback is that a number of informal fallacies, which have been shown to function as rationally warranted heuristics in certain contexts of use (Cummings, 2010), are not amenable to the type of analysis proposed by Walton. Petitio principii or begging the question is among several fallacies which "do not appear to fit specific argumentation schemes, or benefit directly from schemes when it comes to analyzing them" (Walton, 2010: 175). Also, Walton conceives of heuristic reasoning in terms of the bypassing of critical questions which have the potential to reveal logical flaws in argument. However, on the view of fallacies as heuristics discussed in this paper, heuristics are not portrayed as the failure to address certain critical questions. Indeed, there was evidence in this study that subjects do pose and respond to these very questions. Rather, heuristics are characterized in terms of mental shortcuts through expert knowledge domains which lie beyond the cognitive grasp of the lay person. Heuristics on this

${ }^{17}$ With the exception of Hample $(1982,1985,1988)$, few other argumentation and fallacy theorists have attempted to set fallacies within a cognitive framework. One prominent fallacy theorist, John Woods, acknowledges the paucity of work in this area when he states that "an account of fallacies needs to be set in a more general theory of cognitive agency" (2004: xxvi). 
conception are bypassing subject knowledge, not the critical questions that attend argumentation schemes à la Walton. It remains to be seen if Walton's framework can accommodate these critical observations (and a few others discussed in Cummings (2012a)). In the meantime, his account provides a sound starting point for further theoretical exploration of the heuristic function of certain informal fallacies.

Of course, as well as theoretical implications, the findings in this study have implications for how public health workers engage with the public. To the extent that subjects have been shown to display a rational competence in the assessment of the epistemic and logical conditions under which arguments from ignorance and authority are rationally warranted, these conditions may be usefully manipulated by public health practitioners as they attempt to persuade the public to comply with important public health measures. From compliance with control measures to limit the spread of infectious diseases to judgements about the risks and benefits of vaccinations and other medications, the public must be given information that is both comprehensible and rationally compelling if people are to cooperate with public health initiatives and programs. The responses of subjects to the arguments investigated in this study indicate that at least some of the so-called informal fallacies may actually be valuable instruments within the communication tool-kit of public health practitioners.

However, another lesson for public health practitioners contained in this study is that public health interventions should not attempt to bypass the types of rational strategies that this study has shown people to be capable of using. This study has demonstrated how people use arguments from ignorance and authority as quick 'rules of thumb' or heuristics which guide the judgements they make in conditions of uncertainty (the latter principally on account of a lack of knowledge or expertise). It would be a grave mistake on the part of public health practitioners to confuse a lack of scientific knowledge on the part of lay people with a lack of rational competence. While lay reasoners may exhibit a lack of scientific knowledge, this study has shown that they are still very much capable of exercising a rational competence when assessing public health issues. As well as positively exploiting this competence to gain people's compliance with public health interventions, public health practitioners should be very wary indeed of attempts to circumvent it. Any public health practitioner who overlooks this rational competence can expect non-compliance with whatever initiatives and programs are presented to the public. 


\section{Summary}

This study is the first experimental investigation to be undertaken of a group of arguments known as the informal fallacies in a public health context. Specifically, this paper reports the results for two such arguments - the argument from ignorance and the argument from authority - which are part of a larger investigation of the rational strategies used by members of the public during reasoning about public health issues. By varying the epistemic and logical conditions under which these arguments are rationally warranted, it has been possible to demonstrate that lay people make active use of these argument forms as quick 'rules of thumb' or heuristics in their reasoning. This is done with the express purpose of bridging gaps in their scientific knowledge. As well as considering the theoretical implications of this study for models of heuristic reasoning based on informal fallacies, the paper concludes with some remarks about the potential applications of this investigation to work in public health.

\section{Acknowledgements}

The author acknowledges with gratitude the assistance of the following people and organizations in the recruitment of subjects for this study: Peter Homa (Chief Executive, Nottingham University Hospitals NHS Trust), Susan James (Chief Executive, The Royal Derby Hospital), Mark Lewis (Managing Director, John Lewis, Nottingham), Julie Bowley (General Manager, Roko health club, Nottingham), Simon Skelson (General Manager, David Lloyd health club, Nottingham). The assistance of Dr Kevin Perrett (Consultant in Public Health Medicine, Manchester NHS) and Dr Vinod Tohani (formerly Consultant in Communicable Disease Control and Public Health Medicine, Southern Health and Social Services Board, Northern Ireland) is also gratefully acknowledged. Special thanks go to Gavin Brookes (SPUR student, Nottingham Trent University), who played a key role in the formal recruitment activities undertaken as part of this study. 


\section{Appendices}

Appendix 1: Argument from ignorance

\begin{tabular}{|c|c|c|}
\hline Closure & Full Closure & $\begin{array}{c}\text { Incomplete } \\
\text { Closure }\end{array}$ \\
\hline \multirow{2}{*}{$\begin{array}{l}\text { Exhaustive } \\
\text { Search }\end{array}$} & $\begin{array}{l}\text { Full closure } \\
\text { Exhaustive search } \\
\text { Actual scenario } \\
\text { Results: } \\
\text { Accept inference: } 71.4 \% \\
\text { Reject inference (DK): } 22.4 \% \\
\text { Reject inference (other): } 6.2 \%\end{array}$ & $\begin{array}{l}\text { Incomplete closure } \\
\text { Exhaustive search } \\
\text { Actual scenario } \\
\text { Results: } \\
\text { Accept inference: } 25.3 \% \\
\text { Reject inference (DK): } 64.9 \% \\
\text { Reject inference (other): } 9.8 \%\end{array}$ \\
\hline & $\begin{array}{l}\text { Full closure } \\
\text { Exhaustive search } \\
\text { Non-actual scenario } \\
\text { Results: } \\
\text { Accept inference: } 68.4 \% \\
\text { Reject inference (DK): } 29.6 \% \\
\text { Reject inference (other): } 2.0 \%\end{array}$ & $\begin{array}{l}\text { Incomplete closure } \\
\text { Exhaustive search } \\
\text { Non-actual scenario } \\
\text { Results: } \\
\text { Accept inference: } 16.6 \% \\
\text { Reject inference (DK): } 83.4 \% \\
\text { Reject inference (other): } 0 \%\end{array}$ \\
\hline \multirow{2}{*}{$\begin{array}{l}\text { Limited } \\
\text { Search }\end{array}$} & $\begin{array}{l}\text { Full closure } \\
\text { Limited search } \\
\text { Actual scenario } \\
\text { Results: } \\
\text { Accept inference: } 17.6 \% \\
\text { Reject inference (DK): } 80.3 \% \\
\text { Reject inference (other): } 2.1 \%\end{array}$ & $\begin{array}{l}\text { Incomplete closure } \\
\text { Limited search } \\
\text { Actual scenario } \\
\text { Results: } \\
\text { Accept inference: } 20.0 \% \\
\text { Reject inference (DK): } 52.4 \% \\
\text { Reject inference (other): } \\
27.6 \%\end{array}$ \\
\hline & $\begin{array}{l}\text { Full closure } \\
\text { Limited search } \\
\text { Non-actual scenario } \\
\text { Results: } \\
\text { Accept inference: } 33.0 \% \\
\text { Reject inference (DK): } 65.6 \% \\
\text { Reject inference (other): } 1.4 \%\end{array}$ & $\begin{array}{l}\text { Incomplete closure } \\
\text { Limited search } \\
\text { Non-actual scenario } \\
\text { Results: } \\
\text { Accept inference: } 10.3 \% \\
\text { Reject inference (DK): } 88.0 \% \\
\text { Reject inference (other): } 1.7 \%\end{array}$ \\
\hline
\end{tabular}


Appendix 2: Argument from authority

\begin{tabular}{|c|c|c|}
\hline Expertise (1) & Genuine Expertise & Dubious Expertise \\
\hline \multirow{2}{*}{$\begin{array}{l}\text { Impartial } \\
\text { Expertise }\end{array}$} & $\begin{array}{l}\text { Genuine, impartial expertise } \\
\text { Actual scenario } \\
\text { Results: } \\
\text { Valid: } 65.7 \% \\
\text { Moderately valid: } 28.0 \% \\
\text { Not valid at all: } 6.3 \%\end{array}$ & $\begin{array}{l}\text { Dubious, impartial exper- } \\
\text { tise } \\
\text { Actual scenario } \\
\text { Results: } \\
\text { Valid: } 21.5 \% \\
\text { Moderately valid: } 54.5 \% \\
\text { Not valid at all: } 24.0 \%\end{array}$ \\
\hline & $\begin{array}{l}\text { Genuine, impartial expertise } \\
\text { Non-actual scenario } \\
\text { Results: } \\
\text { Valid: } 57.1 \% \\
\text { Moderately valid: } 33.0 \% \\
\text { Not valid at all: } 9.9 \%\end{array}$ & $\begin{array}{l}\text { Dubious, impartial exper- } \\
\text { tise } \\
\text { Non-actual scenario } \\
\text { Results: } \\
\text { Valid: } 6.2 \% \\
\text { Moderately valid: } 41.9 \% \\
\text { Not valid at all: } 51.9 \%\end{array}$ \\
\hline \multirow{2}{*}{$\begin{array}{l}\text { Partial } \\
\text { Expertise }\end{array}$} & $\begin{array}{l}\text { Genuine, partial expertise } \\
\text { Actual scenario } \\
\text { Results: } \\
\text { Valid: } 4.2 \% \\
\text { Moderately valid: } 33.8 \% \\
\text { Not valid at all: } 62.0 \% \\
\end{array}$ & $\begin{array}{l}\text { Dubious, partial expertise } \\
\text { Actual scenario } \\
\text { Results: } \\
\text { Valid: } 3.8 \% \\
\text { Moderately valid: } 26.6 \% \\
\text { Not valid at all: } 69.6 \% \\
\end{array}$ \\
\hline & $\begin{array}{l}\text { Genuine, partial expertise } \\
\text { Non-actual scenario } \\
\text { Results: } \\
\text { Valid: } 12.1 \% \\
\text { Moderately valid: } 52.0 \% \\
\text { Not valid at all: } 35.9 \%\end{array}$ & $\begin{array}{l}\text { Dubious, partial expertise } \\
\text { Non-actual scenario } \\
\text { Results: } \\
\text { Valid: } 3.4 \% \\
\text { Moderately valid: } 37.0 \% \\
\text { Not valid at all: } 59.6 \%\end{array}$ \\
\hline
\end{tabular}

Appendix 3: Subject characteristics

\begin{tabular}{|c|l|}
\hline & $\begin{array}{l}\text { Subject Characteristics } \\
\text { (total }=879 \text { subjects) }\end{array}$ \\
\hline Age & $\begin{array}{l}\text { Average: } 43.8 \text { years } \\
\text { Range: } 18-65 \text { years }\end{array}$ \\
\hline Gender & $\begin{array}{l}\text { Male: } 292 \\
\text { Female: } 587\end{array}$ \\
\hline Education & $\begin{array}{l}\text { University level: } 589 \\
\text { Secondary school level: } 290\end{array}$ \\
\hline
\end{tabular}




\begin{tabular}{|l|l|}
\hline \multicolumn{2}{|c|}{$\begin{array}{c}\text { Subject Characteristics (cont'd) } \\
\text { (total = 879 subjects) }\end{array}$} \\
\hline Ethnicity & White British: 789 \\
& White Irish: 30 \\
& Asian or British Asian Indian: 15 \\
& Asian or British Asian Pakistani: 4 \\
& Black or Black British Caribbean: 3 \\
& Black or Black British African: 3 \\
& Mixed: White and Black Caribbean: 1 \\
& Mixed: White and Black African: 1 \\
& Mixed: White and Asian: 1 \\
& Other: 32 \\
\hline
\end{tabular}

Appendix 4: Argument type: sex and education level (university/secondary)

\begin{tabular}{|c|c|c|c|}
\hline \multirow{2}{*}{ Argument Type } & \multirow{2}{*}{ Response } & Sex & Education \\
\hline & & $\mathrm{M} / \mathrm{F}$ & Uni/Sec \\
\hline $\begin{array}{l}\text { Arg. from ignorance: } \\
\text { Full closure; exhaustive } \\
\text { search } \\
\text { Actual scenario }\end{array}$ & $\begin{array}{l}\text { Accept inference: } \\
\text { Reject inference } \\
\text { (DK): } \\
\text { Other: }\end{array}$ & $\begin{array}{l}69.1 / 79.5 \% \\
23.8 / 16.2 \% \\
7.1 / 4.3 \% \\
\end{array}$ & $\begin{array}{l}71.4 / 71.4 \% \\
24.6 / 17.6 \% \\
4.0 / 11.0 \% \\
\end{array}$ \\
\hline $\begin{array}{l}\text { Arg. from ignorance: } \\
\text { Full closure; exhaustive } \\
\text { search } \\
\text { Non-actual scenario }\end{array}$ & $\begin{array}{l}\text { Accept inference: } \\
\text { Reject inference } \\
\text { (DK): } \\
\text { Other: }\end{array}$ & $\begin{array}{l}60.7 / 71.5 \% \\
36.9 / 26.6 \% \\
2.4 / 1.9 \%\end{array}$ & $\begin{array}{l}64.5 / 76.9 \% \\
33.5 / 20.9 \% \\
2.0 / 2.2 \%\end{array}$ \\
\hline $\begin{array}{l}\text { Arg. from ignorance: } \\
\text { Incomplete closure; limited } \\
\text { search } \\
\text { Actual scenario }\end{array}$ & $\begin{array}{l}\text { Accept inference: } \\
\text { Reject inference } \\
\text { (DK): } \\
\text { Other: }\end{array}$ & $\begin{array}{l}16.7 / 21.4 \% \\
51.2 / 52.9 \% \\
32.1 / 25.7 \% \\
\end{array}$ & $\begin{array}{l}19.0 / 22.2 \% \\
56.5 / 43.3 \% \\
24.5 / 34.5 \% \\
\end{array}$ \\
\hline $\begin{array}{l}\text { Arg. from ignorance: } \\
\text { Incomplete closure; limited } \\
\text { search } \\
\text { Non-actual scenario }\end{array}$ & $\begin{array}{l}\text { Accept inference: } \\
\text { Reject inference } \\
\text { (DK): } \\
\text { Other: }\end{array}$ & $\begin{array}{l}10.4 / 10.3 \% \\
87.0 / 88.6 \% \\
2.6 / 1.1 \%\end{array}$ & $\begin{array}{l}10.0 / 11.0 \% \\
90.0 / 84.0 \% \\
0 / 5.0 \%\end{array}$ \\
\hline $\begin{array}{l}\text { Arg. from ignorance: } \\
\text { Full closure; limited search } \\
\text { Actual scenario }\end{array}$ & $\begin{array}{l}\text { Accept inference: } \\
\text { Reject inference } \\
\text { (DK): } \\
\text { Other: }\end{array}$ & $\begin{array}{l}23.4 / 13.6 \% \\
74.0 / 84.7 \% \\
2.6 / 1.7 \%\end{array}$ & $\begin{array}{l}13.0 / 26.3 \% \\
86.5 / 68.7 \% \\
0.5 / 5.0 \%\end{array}$ \\
\hline $\begin{array}{l}\text { Arg. from ignorance: } \\
\text { Full closure; limited search } \\
\text { Non-actual scenario }\end{array}$ & $\begin{array}{l}\text { Accept inference: } \\
\text { Reject inference } \\
\text { (DK): } \\
\text { Other: }\end{array}$ & $\begin{array}{l}42.1 / 27.1 \% \\
57.9 / 70.6 \% \\
0 / 2.3 \% \\
\end{array}$ & $\begin{array}{l}27.2 / 44.0 \% \\
72.3 / 53.0 \% \\
0.5 / 3.0 \%\end{array}$ \\
\hline $\begin{array}{l}\text { Arg. from ignorance: } \\
\text { Incomplete closure; } \\
\text { exhaustive search } \\
\text { Actual scenario }\end{array}$ & $\begin{array}{l}\text { Accept inference: } \\
\text { Reject inference } \\
\text { (DK): } \\
\text { Other: }\end{array}$ & $\begin{array}{l}19.4 / 27.9 \% \\
74.2 / 60.7 \% \\
6.4 / 11.4 \%\end{array}$ & $\begin{array}{l}22.3 / 31.0 \% \\
68.5 / 57.7 \% \\
9.2 / 11.3 \%\end{array}$ \\
\hline $\begin{array}{l}\text { Arg. from ignorance: } \\
\text { Incomplete closure; } \\
\text { exhaustive search } \\
\text { Non-actual scenario }\end{array}$ & $\begin{array}{l}\text { Accept inference: } \\
\text { Reject inference } \\
\text { (DK): } \\
\text { Other: }\end{array}$ & $\begin{array}{l}10.8 / 19.6 \% \\
89.2 / 80.4 \% \\
0 / 0 \%\end{array}$ & $\begin{array}{l}11.7 / 27.0 \% \\
88.3 / 73.0 \% \\
0 / 0 \%\end{array}$ \\
\hline
\end{tabular}




\section{Louise Cummings}

\begin{tabular}{|c|c|c|c|}
\hline \multirow{2}{*}{ Argument Type } & \multirow{2}{*}{ Response } & Sex & Education \\
\hline & & $\mathrm{M} / \mathrm{F}$ & Uni/Sec \\
\hline $\begin{array}{l}\text { Arg. from authority: } \\
\text { Genuine, impartial } \\
\text { expertise } \\
\text { Actual scenario } \\
\end{array}$ & $\begin{array}{l}\text { Valid: } \\
\text { Moderately valid: } \\
\text { Not valid at all: }\end{array}$ & $\begin{array}{l}62.2 / 67.2 \% \\
28.0 / 27.9 \% \\
9.8 / 4.9 \%\end{array}$ & $\begin{array}{l}63.5 / 71.1 \% \\
29.4 / 24.5 \% \\
7.1 / 4.4 \%\end{array}$ \\
\hline $\begin{array}{l}\text { Arg. from authority: } \\
\text { Genuine, impartial } \\
\text { expertise } \\
\text { Non-actual scenario }\end{array}$ & $\begin{array}{l}\text { Valid: } \\
\text { Moderately valid: } \\
\text { Not valid at all: }\end{array}$ & $\begin{array}{l}48.8 / 60.2 \% \\
42.7 / 28.9 \% \\
8.5 / 10.9 \%\end{array}$ & $\begin{array}{l}57.1 / 56.3 \% \\
34.7 / 28.7 \% \\
8.2 / 15.0 \%\end{array}$ \\
\hline $\begin{array}{l}\text { Arg. from authority: } \\
\text { Genuine, partial expertise } \\
\text { Actual scenario }\end{array}$ & $\begin{array}{l}\text { Valid: } \\
\text { Moderately valid: } \\
\text { Not valid at all: }\end{array}$ & $\begin{array}{l}3.6 / 4.4 \% \\
41.0 / 30.6 \% \\
55.4 / 65.0 \%\end{array}$ & $\begin{array}{l}3.1 / 6.6 \% \\
31.8 / 37.4 \% \\
65.1 / 56.0 \%\end{array}$ \\
\hline $\begin{array}{l}\text { Arg. from authority: } \\
\text { Genuine, partial expertise } \\
\text { Non-actual scenario }\end{array}$ & $\begin{array}{l}\text { Valid: } \\
\text { Moderately valid: } \\
\text { Not valid at all: }\end{array}$ & $\begin{array}{l}14.0 / 10.8 \% \\
54.4 / 50.6 \% \\
31.6 / 38.6 \%\end{array}$ & $\begin{array}{l}10.5 / 15.0 \% \\
50.5 / 55.0 \% \\
39.0 / 30.0 \%\end{array}$ \\
\hline $\begin{array}{l}\text { Arg. from authority: } \\
\text { Dubious, partial expertise } \\
\text { Actual scenario }\end{array}$ & $\begin{array}{l}\text { Valid: } \\
\text { Moderately valid: } \\
\text { Not valid at all: }\end{array}$ & $\begin{array}{l}6.3 / 2.3 \% \\
23.2 / 28.7 \% \\
70.5 / 69.0 \%\end{array}$ & $\begin{array}{l}1.1 / 9.1 \% \\
20.9 / 37.4 \% \\
78.0 / 53.5 \%\end{array}$ \\
\hline $\begin{array}{l}\text { Arg. from authority: } \\
\text { Dubious, partial expertise } \\
\text { Non-actual scenario }\end{array}$ & $\begin{array}{l}\text { Valid: } \\
\text { Moderately valid: } \\
\text { Not valid at all: }\end{array}$ & $\begin{array}{l}7.7 / 1.5 \% \\
37.4 / 36.8 \% \\
54.9 / 61.7 \%\end{array}$ & $\begin{array}{l}1.6 / 7.0 \% \\
37.3 / 36.4 \% \\
61.1 / 56.6 \%\end{array}$ \\
\hline $\begin{array}{l}\text { Arg. from authority: } \\
\text { Dubious, impartial } \\
\text { expertise } \\
\text { Actual scenario } \\
\end{array}$ & $\begin{array}{l}\text { Valid: } \\
\text { Moderately valid: } \\
\text { Not valid at all: }\end{array}$ & $\begin{array}{l}20.0 / 22.3 \% \\
55.6 / 54.3 \% \\
24.4 / 23.4 \%\end{array}$ & $\begin{array}{l}24.0 / 16.9 \% \\
54.7 / 54.7 \% \\
21.3 / 28.4 \%\end{array}$ \\
\hline $\begin{array}{l}\text { Arg. from authority: } \\
\text { Dubious, impartial } \\
\text { expertise } \\
\text { Non-actual scenario }\end{array}$ & $\begin{array}{l}\text { Valid: } \\
\text { Moderately valid: } \\
\text { Not valid at all: }\end{array}$ & $\begin{array}{l}11.1 / 4.0 \% \\
33.3 / 45.7 \% \\
55.6 / 50.3 \%\end{array}$ & $\begin{array}{l}6.2 / 6.3 \% \\
42.3 / 41.1 \% \\
51.5 / 52.6 \%\end{array}$ \\
\hline
\end{tabular}

\section{References}

American Public Health Association (1990) "Technical report: Public health policy-making in the presence of incomplete evidence." American Journal of Public Health, 80 (6): 74650.

Berry, D. (2004) Risk, Communication and Health Psychology, Milton Keynes: Open University Press.

Blair, J.A. (2012) "Argumentation as rational persuasion." Argumentation, 26 (1): 71-81.

Brown, P., Cathala, F., Raubertas, R.F., Gajdusek, D.C. and Castaigne, P. (1987) "The epidemiology of Creutzfeldt-Jakob 
disease: Conclusion of a 15-year investigation in France and review of the world literature." Neurology, 37 (6): 895-904.

Browne, K. (2005) "Snowball sampling: Using social networks to research non-heterosexual women." International Journal of Social Research Methodology, 8 (1): 47-60.

Cummings, L. (2002) "Reasoning under uncertainty: The role of two informal fallacies in an emerging scientific inquiry." Informal Logic, 22 (2): 113-136.

Cummings, L. (2004) "Analogical reasoning as a tool of epidemiological investigation." Argumentation, 18 (4): 427-444.

Cummings, L. (2005) "Giving science a bad name: Politically and commercially motivated fallacies in BSE inquiry." $\mathrm{Ar}$ gumentation, 19 (2): 123-143.

Cummings, L. (2009) "Emerging infectious diseases: Coping with uncertainty." Argumentation, 23 (2): 171-188.

Cummings, L. (2010) Rethinking the BSE Crisis: A Study of Scientific Reasoning under Uncertainty, Dordrecht: Springer.

Cummings, L. (2011) "Considering risk assessment up close: The case of bovine spongiform encephalopathy." Health, Risk \& Society, 13 (3): 255-275.

Cummings, L. (2012a) "Scaring the public: Fear appeal arguments in public health reasoning." Informal Logic, 32 (1): 2550 .

Cummings, L. (2012b) "The contribution of informal logic to public health." Perspectives in Public Health, 132 (2): 66-67.

Cummings, L. (2012c) "The public health scientist as informal logician." International Journal of Public Health, 57 (3): 649-650.

Cummings, L. (2013) "Public health reasoning: Much more than deduction." Archives of Public Health, 71 (1): 25.

Cummings, L. (2014a) "The 'trust' heuristic: Arguments from authority in public health." Health Communication, to appear.

Cummings, L. (2014b) "Circles and analogies in public health reasoning." Inquiry, to appear.

Cummings, L. (2014c) "Analogical reasoning in public health." Journal of Argumentation in Context, to appear.

Cummings, L. (2014d) "Coping with uncertainty in public health: The use of heuristics." Public Health, to appear.

Doble, J. (1995) "Public opinion about issues characterized by technological complexity and scientific uncertainty." Public Understanding of Science, 4 (2): 95-118.

Eemeren, F.H. van, Garssen, B. and Meuffels, B. (2009) Fallacies and Judgments of Reasonableness: Empirical Research concerning the Pragma-Dialectical Discussion Rules, Dordrecht: Springer. 
Finocchiaro, M.A. (1994) "Two empirical approaches to the study of reasoning." Informal Logic, 16 (1): 1-21.

Frewer, L.J., Howard, C., Hedderley, D. and Shepherd, R. (1996) "What determines trust in information about foodrelated risks? Underlying psychological constructs." Risk Analysis, 16 (4): 473-486.

Hample, D. (1982) "Dual coding, reasoning and fallacies." Journal of the American Forensic Association, 19 (2): 59-78.

Hample, D. (1985) "A third perspective on argument." Philosophy and Rhetoric, 18 (1):1-22.

Hample, D. (1988) "Argument: public and private, social and cognitive." Journal of the American Forensic Association, 25 (1): 13-19.

Johnson, B.B. (2005) "Testing and expanding a model of cognitive processing of risk information." Risk Analysis, 25 (3): 631-650.

Klahr, D. (2000) Exploring Science: The Cognition and Development of Discovery Processes, Cambridge, MA: The MIT Press.

National Science Board (2010) Science and Engineering Indicators 2010, Arlington, VA: National Science Foundation.

Noy, C. (2008) "Sampling knowledge: The hermeneutics of snowball sampling in qualitative research." International Journal of Social Research Methodology, 11 (4): 327-344.

Poortinga, W. and Pidgeon, N.F. (2003) "Exploring the dimensionality of trust in risk regulation." Risk Analysis, 23 (5): 961-972.

Siegrist, M. and Cvetkovich, G. (2000) "Perception of hazards: The role of social trust and knowledge." Risk Analysis, 20 (5): 713-720.

Trumbo, C.W. (2002) "Information processing and risk perception: An adaptation of the heuristic-systematic model." Journal of Communication, 52 (2): 367-382.

Tversky, A. and Kahneman, D. (1974) "Judgement under uncertainty: Heuristics and biases." Science, 185 (4157): 11241131.

Tversky, A. and Kahneman, D. (2004) "Belief in the law of small numbers." In E. Shafir (Ed.), Preference, Belief and Similarity: Selected Writings by Amos Tversky, pp. 193-202. Cambridge, MA: The MIT Press.

Vaughan, E. and Tinker, T. (2009) "Effective health risk communication about pandemic influenza for vulnerable populations." American Journal of Public Health, 99 (S2): S324S332. 
Walton, D.N. (1985) "Are circular arguments necessarily vicious?" American Philosophical Quarterly, 22 (4): 263-274.

Walton, D.N. (1992) "Nonfallacious arguments from ignorance." American Philosophical Quarterly, 29 (4): 381-387.

Walton, D.N. (1995) A Pragmatic Theory of Fallacy, Tuscaloosa, Alabama: The University of Alabama Press.

Walton, D.N. (1997) Appeal to Expert Opinion: Arguments from Authority, University Park, PA: The Pennsylvania State University Press.

Walton, D.N. (2010) "Why fallacies appear to be better arguments than they are." Informal Logic, 30 (2): 159-184.

Willard, C.A. (1990) "Authority." Informal Logic, 12 (1): 11-22.

Wilson, C., Evans, G., Leppard, P. and Syrette, J. (2004) "Reactions to genetically modified food crops and how perception of risks and benefits influences consumers' information gathering." Risk Analysis, 24 (5): 1311-1321.

Woods, J. (1995) “Appeal to force.” In H.V. Hansen \& R.C. Pinto (eds) Fallacies: Classical and Contemporary Readings, pp. 240-250. University Park, PA: The Pennsylvania State University Press.

Woods, J. (2004) The Death of Argument: Fallacies in AgentBased Reasoning. Dordrecht: Kluwer Academic Publishers. 